\section{Cornell Student Chapter Receives Charter}

Anthony $Y_{u}$

Vice President.

Cornell University Student Chapter

On October 24, the Cornell Student Chapter of MRS welcomed MRS President Elton Kaufmann to the university for an afternoon of discussion, a seminar, and inauguration of the chapter. While the Cornell Chapter was subsequently recognized in December at the Fall Meeting, this meeting at Cornell gave a large number of students an opportunity to learn first hand about the workings and goals of the Materials Research Society.

During the early afternoon, the chapter held an informal discussion session with Kaufmann. Students and faculty were informed of the myriad of activities which the Society sponsors. The discussion included a history of MRS, showing how the Society was established to provide an interdisciplinary forum for physicists and chemists as well as materials scientists. The continuing role of MRS in these fields was illustrated by the announcement of the start of the Society's new journal, Journal of Materials Research.

Following a technical seminar by Kaufmann on his current research, the Student Chapter was presented its Certificate of Charter. Accepting the charter was Chapter President Glen Harmon, a senior in the department of Materials Science and Engineering. Also present for the charter ceremony were Chapter Vice-President Anthony Yu, President-Elect Toni Koch and

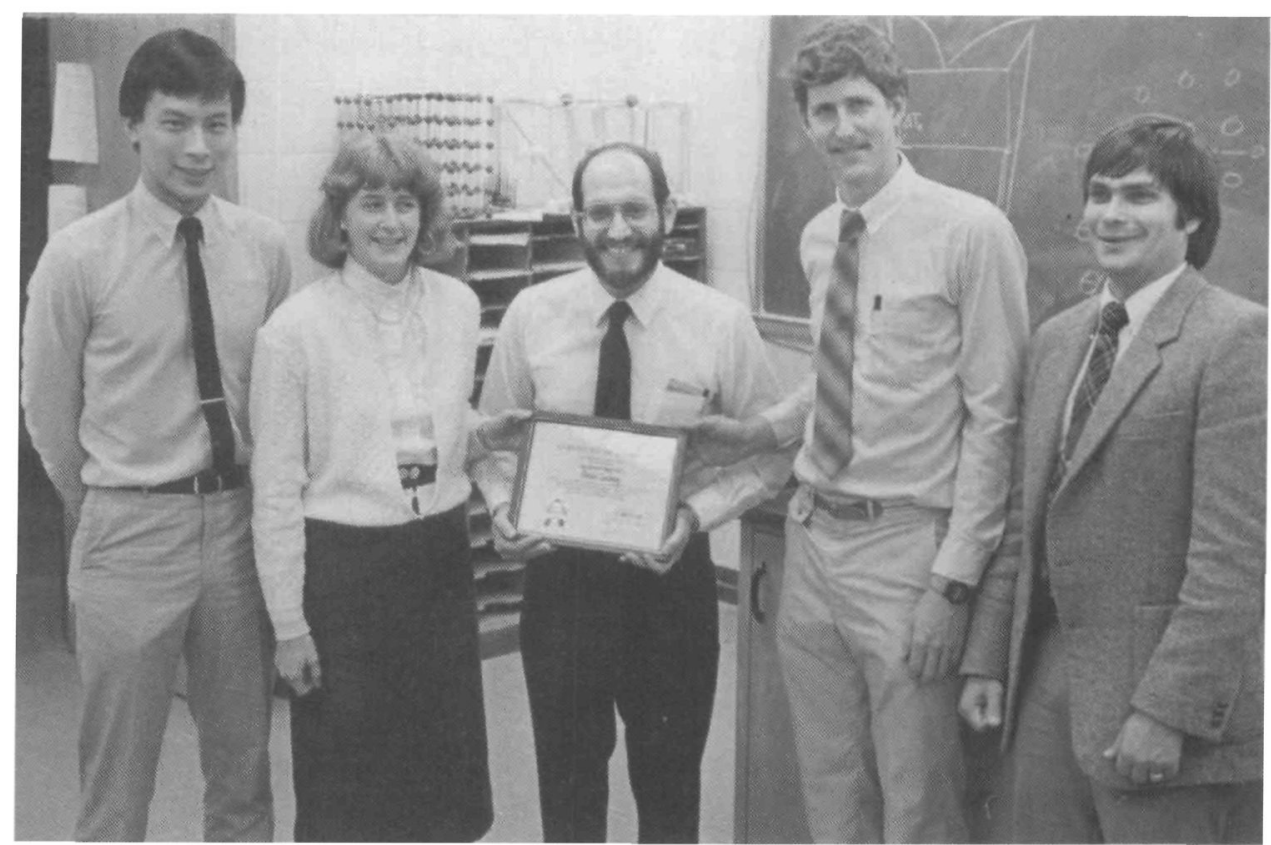

Cornell Univerity MRS Student Chapter receives Certificate of Charter. At the ceremony were (left to right): Anthony Yu, Chapter Vice President; Toni Koch, Chapter President-Elect; Elton Kaufmann, MRS President; Glenn Harmon, Chapter President; and Prof. Michael Thompson, Chapter Advisor.

Chapter Advisor, Prof. Michael Thompson. Others present at the seminar included students and faculty from various fields at Cornell, including materials science, electrical engineering, applied physics, and chemical engineering.

After Kaufmann's visit, the Chapter enthusiastically planned for the Fall Meeting in Boston. Using a travel assistance grant from MRS, 14 members of the Cornell Chapter were able to attend the meeting.

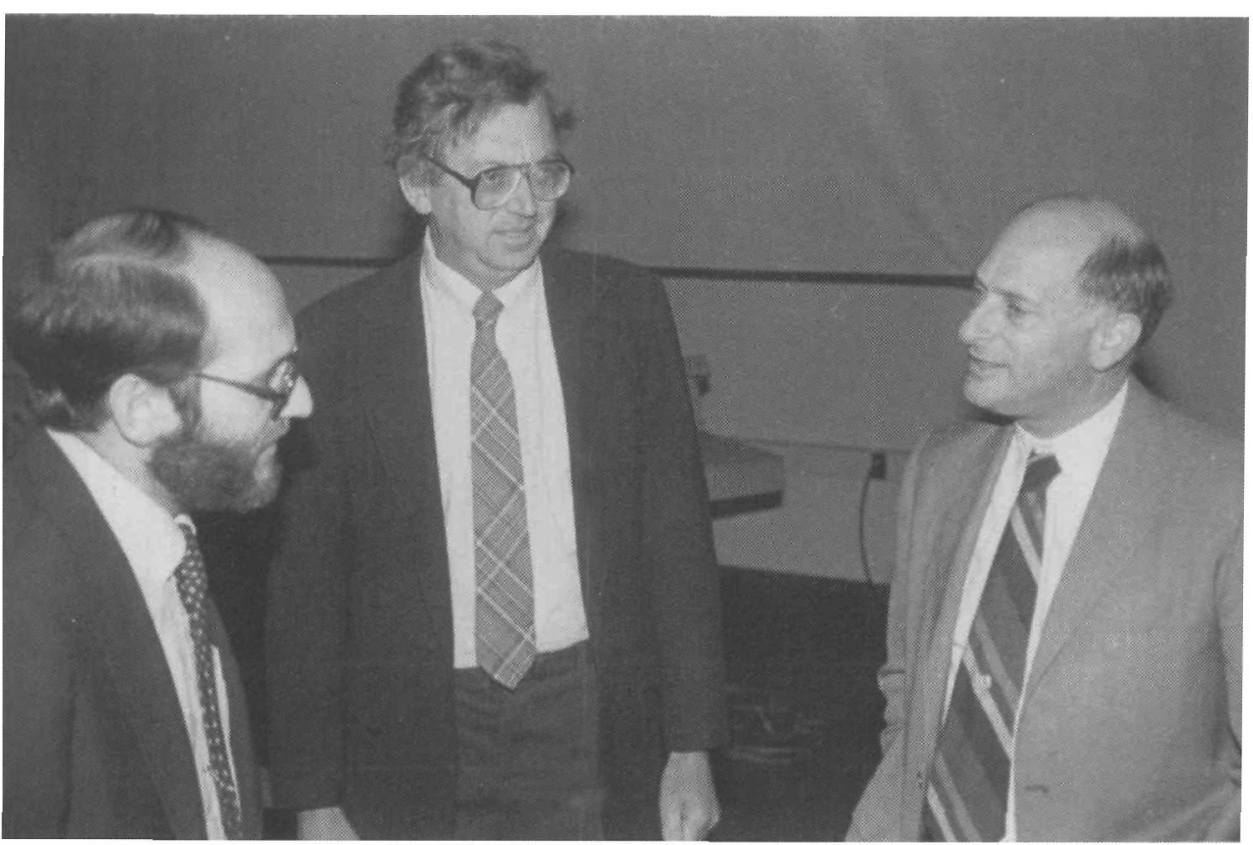

RPI Student Chapter Faculty Advisor R.K. MacCrone (center) discusses upcoming chapter activities with Chairman, Materials Engineering, M.E. Glicksman (right) and Elton Kaufmann (left).
Many of these students also worked as projectionists to support their travel. All of the participants found the meeting amazingly large and diverse, and discovered the common difficulty of deciding which sessions to attend. Given the proximity of Boston and Cornell, the members of the Cornell Student Chapter hope to make the Fall Meeting an annual part of their events.

\section{RPI Student Chapter Holds First Meeting}

The first meeting of the newly formed MRS Student Chapter at Rensselaer Polytechnic Institute, Troy, New York, was held in late October. In keeping with the MRS tradition of holding an on-campus presentation of Student Chapter charters as well as a presentation of the charter at an international MRS meeting, Chapter President Steve Bilodeau received the charter from 1985 MRS President Elton Kaufmann. (See also "New Sections and Chapters Recognized at Fall Meeting" in this issue.)

M.E. Glicksman, Chairman, Materials Engineering, addressed the group at the beginning of the meeting, and Chemistry Department Chairman S.E. Wiberley then discussed the role of MRS and its importance to the members of the Chapter. Kaufmann presented a seminar on the rapid solidification of metals.

Chapter Faculty Advisor R.F. MacCrone reports that the students plan to become affiliated with other campus technical societies with interests in materials re-

Continued 